\title{
Space agency funding defies downturn
}

\section{THE HAGUE, THE NETHERLANDS}

"Just look at the smile on my face," beams David Southwood, head of science and robotic exploration at the European Space Agency (ESA), minutes after the outcome of a crucial summit between the ministers of the agency's 18 member states.

Despite the financial crisis, the ministers agreed to commit $€ 10$ billion (US $\$ 12.8$ billion) to ESA, a $21 \%$ increase on the sum promised at the last ministerial meeting in 2005. The funding secures almost everything that was on ESA's wish list, including a spending increase for its flagship science programme.

The summit allocated $€ 831$ million (to 2018) for a joint ESA-European Union (EU) programme dubbed the GMES/Kopernikus, a network of satellites that would make Europe the world leader in Earth monitoring. It also allocated $€ 943$ million (to 2020) for nextgeneration meteorological satellites; $€ 1.37$ billion to operate and carry out experiments on the International Space Station; and $€ 357$ million (to 2011) to start design studies for a series of more powerful European space launch vehicles. The meeting was a "complete success", according to a visibly relieved Jean-Jacques Dordain, director general of ESA.

No final decision was reached on ExoMars, an ambitious $€ 1$ 1.2-billion plan to send a rover to Mars. But cancellation - which some had feared possible - was avoided. Ministers agreed to ESA's proposed postponement of the launch from 2013 to 2016, but gave the programme $€ 850$ million, enough for work to begin, while capping ESA's overall contribution at $€ 1$ billion up to its launch. A final funding decision will be taken in September 2009 following a technical review and discussions of how much NASA and other international partners can contribute to make up the shortfall in the programme's budget.

\section{Space for citizens}

ESA ministerial meetings are the high point of Europe's space calendar. The multiannual budgets that they fix give projects long-term stability, but can also mean make-or-break for missions. They can be nail-biting affairs for those with missions on the table, often ending in late-night negotiations to hammer out deals.

This year's meeting, held in The Hague in the Netherlands on 25 and 26 November, was upbeat from the start, however. The summit backed 30 new programmes, twice as many as at the last ministerial meeting in Berlin. And ESA will open its first research centre in Britain,

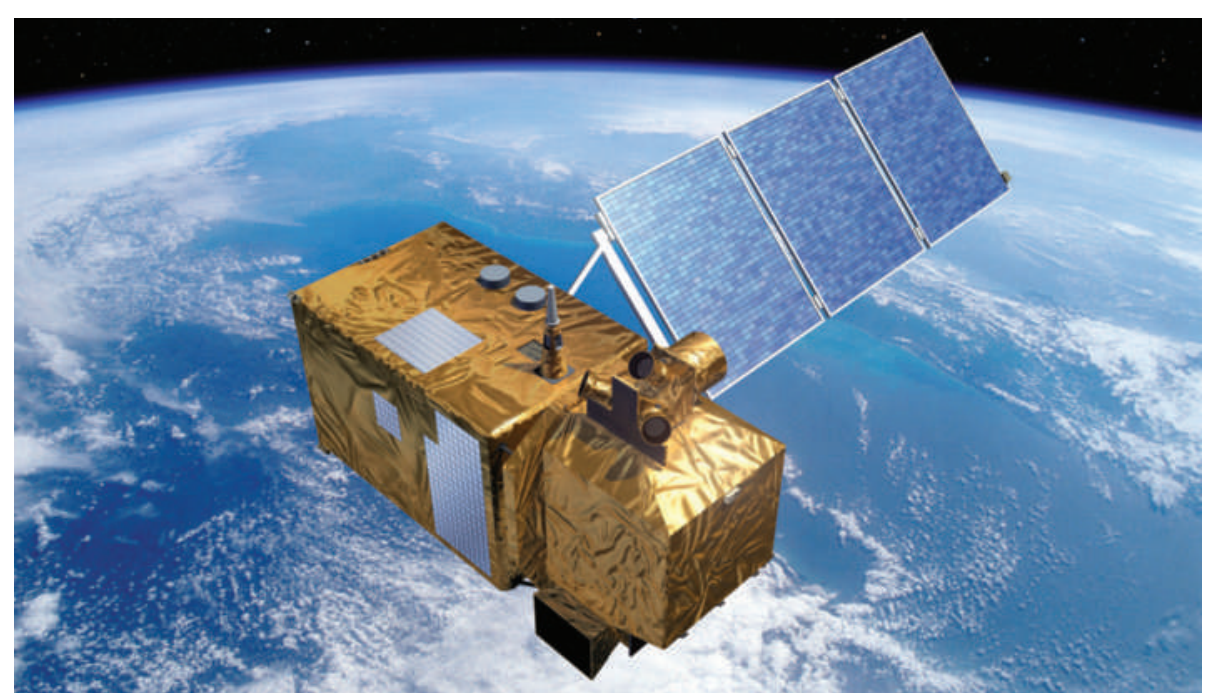

The planned GMES Earth-monitoring programme has won funding from the European Space Agency.

with a facility on the Harwell innovation campus near Oxford focusing on climatechange science and space robotics.

The current financial crisis helped win consensus at the summit, ministers say. "We must invest in the future," says Valérie Pécresse, France's science and education minister. "It is one of the answers to the crisis."

There had also been strong political impetus to make the meeting a success following an EU endorsement this September that space was an important priority. But political support has its price. Pécresse made it clear that governments want ESA's emphasis to be on space activities that benefit citizens, such as the Galileo navigation-satellite system and the GMES/Kopernikus programme.

GMES/Kopernikus will use several families of satellites to provide real-time data on, for example, air quality, water pollution and natural disasters, while generating cross-calibrated, long-term data sets on the state of the planet and its atmosphere.

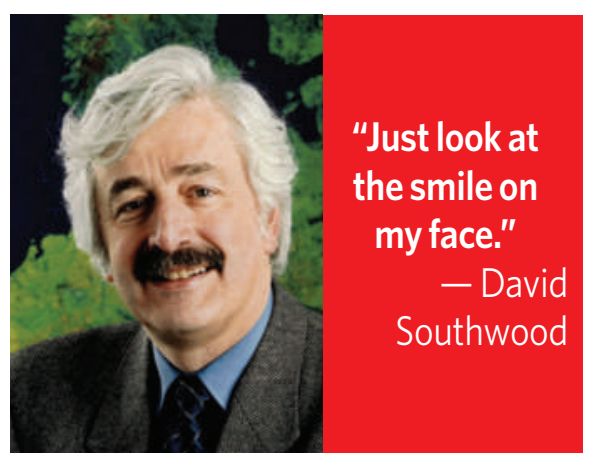

The next phase of the project, the launch of the second wave of satellites, which was initially budgeted at $€ 1$ billion until 2017, was threatened a few weeks ago when Italy reduced its $25 \%$ stake to $14 \%$ (€120 million). Italy and France also argued that the costs of the secondary 'b-unit' satellites in each family should be borne by the EU (see Nature 455, 1013; 2008).

ESA compromised by asking for $€ 857$ million, with Britain increasing its share from 1.5\% to $10 \%$ (€87.5 million). The b-units will still be built by ESA, with the EU paying for their launch - delayed by a year to start from 2015 — and in-orbit validation.

ESA also won its requested 3.5\% annual boost to its science-programme budget, slightly more than it negotiated in 2005. Southwood is satisfied with ministers' consistent support, which was so often lacking in the 1990s when space science was a frequent target for cuts.

This keeps all of ESA's planned science missions on track, including the Herschel/ Planck space telescope and the BepiColombo probe to Mercury. It will also allow two more missions to launch around 2016, says Southwood. These will be selected in 2011 from four competitors: PLATO, a telescope to search for Earth-like planets; Cross-Scale, to study fundamental space plasma processes; the Euclid dark-matter mapper; and a solar orbiter. "With this money," smiles Southwood, "I can face the world and say, 'Look, we aren't kidding in space science."

Declan Butler

See also Editorial, page 546. 